\title{
On the importance of self-secondaries
}

\author{
Zhiyong Xiao ${ }^{1,2^{*}}$
}

\begin{abstract}
Self-secondaries are secondary craters that are formed on both the continuous ejecta deposits and interior of the parent crater. The possible existence of self-secondaries was proposed in the late 1960s, but their identity, formation mechanism, and importance were not revisited until the new generation of high-resolution images for the Moon have recently became available. Possible self-secondary crater populations have now been recognized not only on the Moon, but also on Mercury, Mars, 1 Ceres, 4Vesta, and satellites of the ice giants. On the Moon and terrestrial planets, fragments that form self-secondaries are launched with high ejection angles via spallation during the early cratering process, so that self-secondaries can be formed both within the crater and on the continuous ejecta deposits at the end of the cratering process. Self-secondaries potentially possess profound effects on the widely used agedetermination technique using crater statistics in planetary geology, because (1) self-secondaries cause nonuniform crater density across the continuous ejecta deposits, which cannot be solely explained by the effect of different target properties on crater size-frequency distributions; (2) crater chronologies for both the Moon and the other terrestrial bodies are largely based on crater counts on the continuous ejecta deposits of several young lunar craters. The effect of self-secondaries on crater chronology can be well addressed after the spatial distribution, size-frequency distribution, and density evolution of self-secondaries are resolved.
\end{abstract}

Keywords: Secondary crater, Crater chronology, Impact cratering, Planetary geology

\section{Introduction}

High velocity impact between celestial materials is arguably the most fundamental process in the formation and evolution of the Solar System. Impact cratering has continuously occurred on all the solar system bodies ever since their formation and impact craters are the most common landscapes on bodies that have solid surfaces (Melosh 1989). Just like fossils on Earth, impact structures and their associated ejecta are the basic stratigraphic marker when studying the geological evolution of extraterrestrial bodies (e.g., Wilhelms 1987).

The continuous accumulation of impact craters causes higher crater densities on older surfaces, so that relative ages of different geological units on a same planetary body can be compared by studying their crater densities, e.g., the relatively old cratonic areas on Earth have

\footnotetext{
*Correspondence: zyxiao@cug.edu.cn

1 Planetary Science Institute, School of Earth Sciences, China University

of Geosciences (Wuhan), \#388 Lumo Road, Hongshan District,

Wuhan 430074, Hubei, China

Full list of author information is available at the end of the article
}

a higher density of impact craters than the global average (e.g., French 1998). Assuming a known formation rate for different-sized craters, crater densities observed on planetary surfaces can be translated to absolute ages (e.g., Hartmann 1965). This concept was fully established during the Apollo era, when large amount of imagery for the Moon and samples collected from several known locations by the Apollo and Luna missions were obtained (Fig. 1). Impact craters on several different-aged lunar surfaces were recognized to have the same size-frequency distributions (i.e., SFD; Fig. 1b), indicating that the relative production rates for different-sized craters (i.e., crater production function; PF) have been more or less stable during a significant part of the lunar history (Neukum et al. 1975). Radiometric ages for Apollo and Luna samples have built the bridge between crater densities and surface ages (Fig. 1c; Neukum 1983), i.e., the crater chronology functions (i.e., CF). The combination of crater production and chronology functions could derive crater density isochrones, i.e., the size-frequency distribution of impact craters formed on different-aged surfaces (Fig. 1d). Therefore, absolute model ages can 

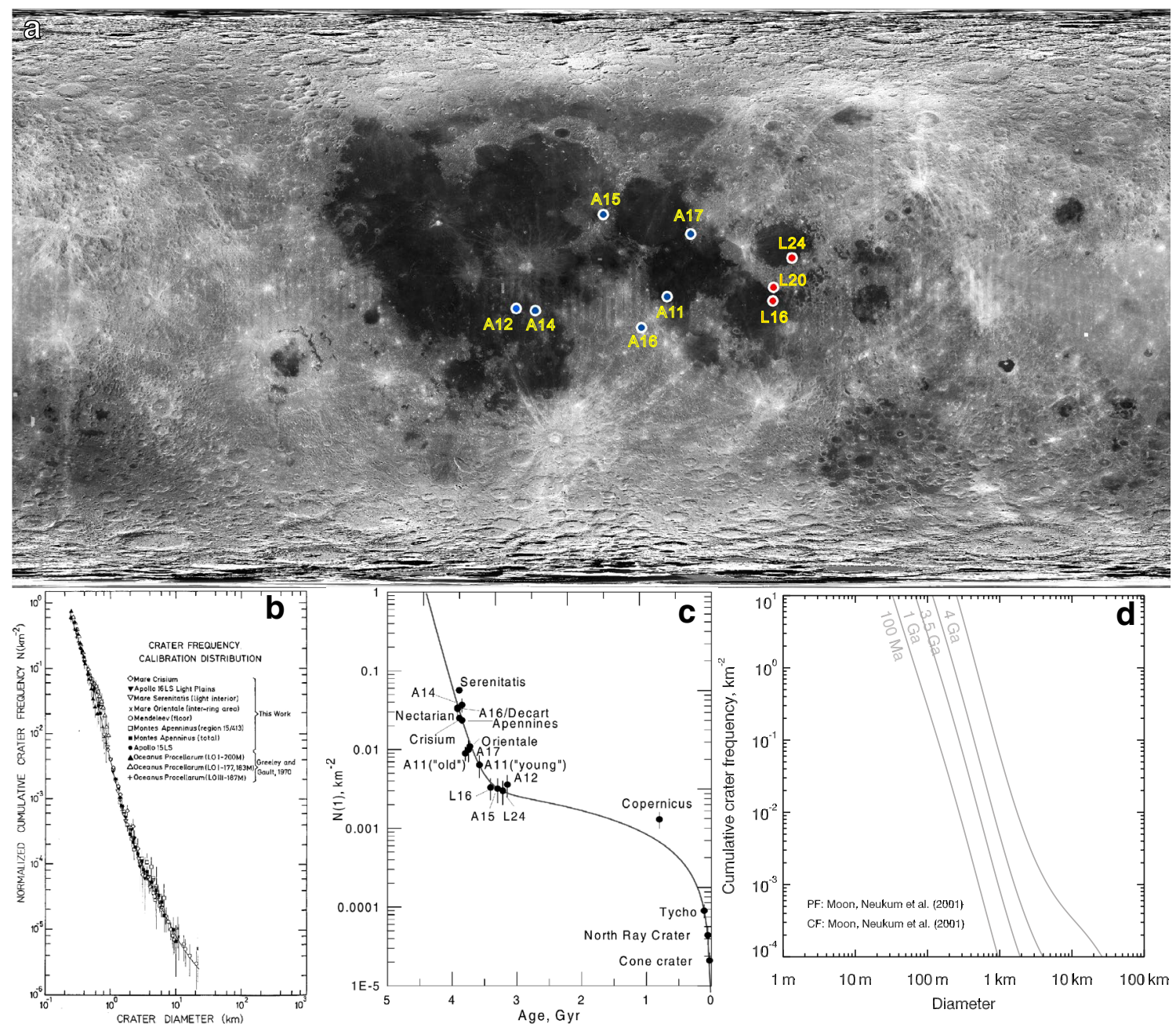

Fig. 1 a The Apollo (denoted as A) and Luna (denoted as L) sampling sites on the Moon. The base image is the global mosaic of the Moon that is obtained by the Lunar Orbiter missions and the Clementine spacecraft (59 m/pixel; equirectangular projection). b Crater size-frequency distributions at difference-aged lunar surfaces can be aligned after a same polynomial function. The labels of the counting areas can be read from the original plot in Neukum et al. (1975). c Calibration points used to construct the lunar crater chronology function (Stöffler et al. 2006). d Examples of isochrones of crater size-frequency distribution on different-aged lunar surfaces. The production and chronology functions are based on those proposed by Neukum et al. (2001)

be obtained for surfaces outside of the Luna and Apollo landing sites by finding the position of the observed surface crater SFD within the lunar crater isochrones. Moving further, impact flux ratios between the Moon and the other solar system bodies, which are predicted by orbital dynamics could be used to translate the lunar crater chronology to the other Solar System bodies (e.g., Hartmann 1977), so absolute model ages for geological units on these bodies could be obtained as well (e.g., Neukum et al. 2001).

The first-order reliability of crater statistics in dating planetary surfaces has been successfully testified in many cases. For example, crater statistics derived an average age of $~ 3.6$ Gyr for the lunar maria (Hartmann 1965), which was subsequently confirmed by the Apollo and Luna samples. So far, crater statistics have been the major technique used in estimating ages for planetary surfaces. This technique has been greatly improved with new advances in sample analyses methods, cratering mechanics, orbital dynamics, and multiwavelengths high-resolution datasets obtained by recent lunar and deep space explorations. A review on the establishment, usage and new advances of this technique is detailed by Fassett (2016). It is not overstated that this technique has built most of the time frames 
used in studying the geological, geophysical, and geochemical evolution of solar system bodies.

Many uncertainties, however, exist in the lunar crater chronology function, which is the basis for the CFs on the other planetary bodies since the Moon is the only extraterrestrial body from which samples with known locations are obtained. For example, there is no sample control for lunar surfaces that are formed between $\sim 3.2$ to $1 \mathrm{Ga}$, so that the impact flux during this time is not known (Fig. 1c); large controversies exist in assigning sample ages greater than $\sim 3.8$ Gyr to large lunar basins such as Orientale, Imbrium, Serenitatis, Crisium, and Nectaris (cf. Stöffler et al. 2006); and the radiometric ages for the Copernicus and Tycho craters were not based on their in situ impact melt rocks, but based on samples collected from their distant impact rays (cf. Stöffler et al. 2006). Likewise, debates have been persistent regarding the possible change of crater production functions with time on both the Moon and the other bodies. For example, the impactor population, thus production crater population might have been changed with time in the inner solar system (Strom et al. 2005), so that the prevailing crater statistics method may not be able to date surfaces older than $\sim 3.8 \mathrm{Gyr}$; the outer solar system bodies have different cratering history with the inner solar system bodies so that the lunar crater chronology cannot be simply mirrored to the outer solar system (Strom et al. 2015).

Besides many more complexities that may introduce uncertainties in crater count results (e.g., homogeneity of study area, personal bias in recognizing craters, image resolution, surface illumination condition, topography wavelength, and equilibrium condition; see a recent review by Williams et al. 2017), one of the major concerns about the reliability of both the crater chronology and the actual application of this technique in deriving model ages is the possible contamination by secondary craters (i.e., secondaries). Secondaries are craters formed by the landing of impact ejecta around the parent crater. Unlike primary craters (i.e., primaries) that are formed by projectiles with heliocentric orbits (i.e., asteroids and comets), typical secondaries are not circular in morphology or random in the spatial distribution, as they normally occur in clusters or herringbone-shaped chains and exhibit irregularly shaped morphology, such as shallow floors, asymmetric rims, and central mounds (e.g., Oberbeck and Morrison 1974; Schultz and Gault 1985). Traditionally, secondaries are classified into two groups according to their locations to the parent crater (e.g., Schultz and Singer 1980): (1) continuous secondaries facies are located just beyond the continuous ejecta deposits (Fig. 2b), where clusters and chains of secondaries (up to $\sim 5 \%$ diameter of the parent crater) can extend to $\sim 4$ parent-crater-radii from the rim of the parent crater; (2) distant secondaries beyond the continuous secondaries facies can have near global coverage (Fig. 2a), and they are mainly composed by patches of secondaries and those within impact rays are most-easily recognized (Fig. 2c). While most of these secondaries can be confidently recognized and excluded when dating planetary surfaces using crater statistics, some of them have identical plane morphology with similar-sized primaries (Xiao et al. 2014), and they may no longer be differentiable from primaries once been degraded (Xiao 2016).

The potential trouble-making secondaries to the crater chronology are a subgroup of distant secondaries that do not occur in obvious clusters or chains and have identical plane morphology with similar-sized primaries. These secondaries are termed as background secondaries or field secondaries (e.g., McEwen and Bierhaus 2006). The high efficiency in the production of distant secondaries have been noticed on Mercury (Strom et al. 2011; Xiao 2016), the Moon (e.g., Hirata and Nakamura 2006; Dundas and McEwen 2007; Robinson et al. 2015), Mars (e.g., McEwen et al. 2005; Robbins and Hynek 2014), and Europa (Bierhaus et al. 2005). However, whether or not background secondaries dominate crater populations within their diameter ranges (e.g., $<\sim 1 \mathrm{~km}$ on the Moon and Mercury; $<8 \mathrm{~km}$ on Mercury) has been a debate for more than half a century (e.g., Shoemaker 1962; Neukum and Ivanov 1994; McEwen and Bierhaus 2006; Hartmann 2007; Werner et al. 2009; Strom et al. 2011; Xiao and Strom 2012; Williams et al. 2014; Xie et al. 2017). The resolution of this debate is critically important to both the crater chronology and the application of crater statistics, because: (1) crater counts at the Apollo and Luna landing sites are dominated by sub-kilometer or kilometer diameter crater populations, so that possible contamination by background secondaries might have caused larger crater densities than those of the primary crater populations; (2) geological study for small planetary surface units are recently being enabled with more and more high-resolution images obtained, but only small craters are visible on small geological units, thus the effect of potential background secondaries cannot be ignored. Although new observations on Mercury suggest that background secondaries do abundantly exist outside of impact rays (Xiao 2016), solid observations for populations of background secondaries and their SFD are still lacking, since in theory, background secondaries are not distinguishable from primaries in terms of morphology and spatial distribution. Therefore, there have been three different schools in this debate: (1) Background secondaries dominate small crater populations on Mercury (Strom et al. 2011), the 

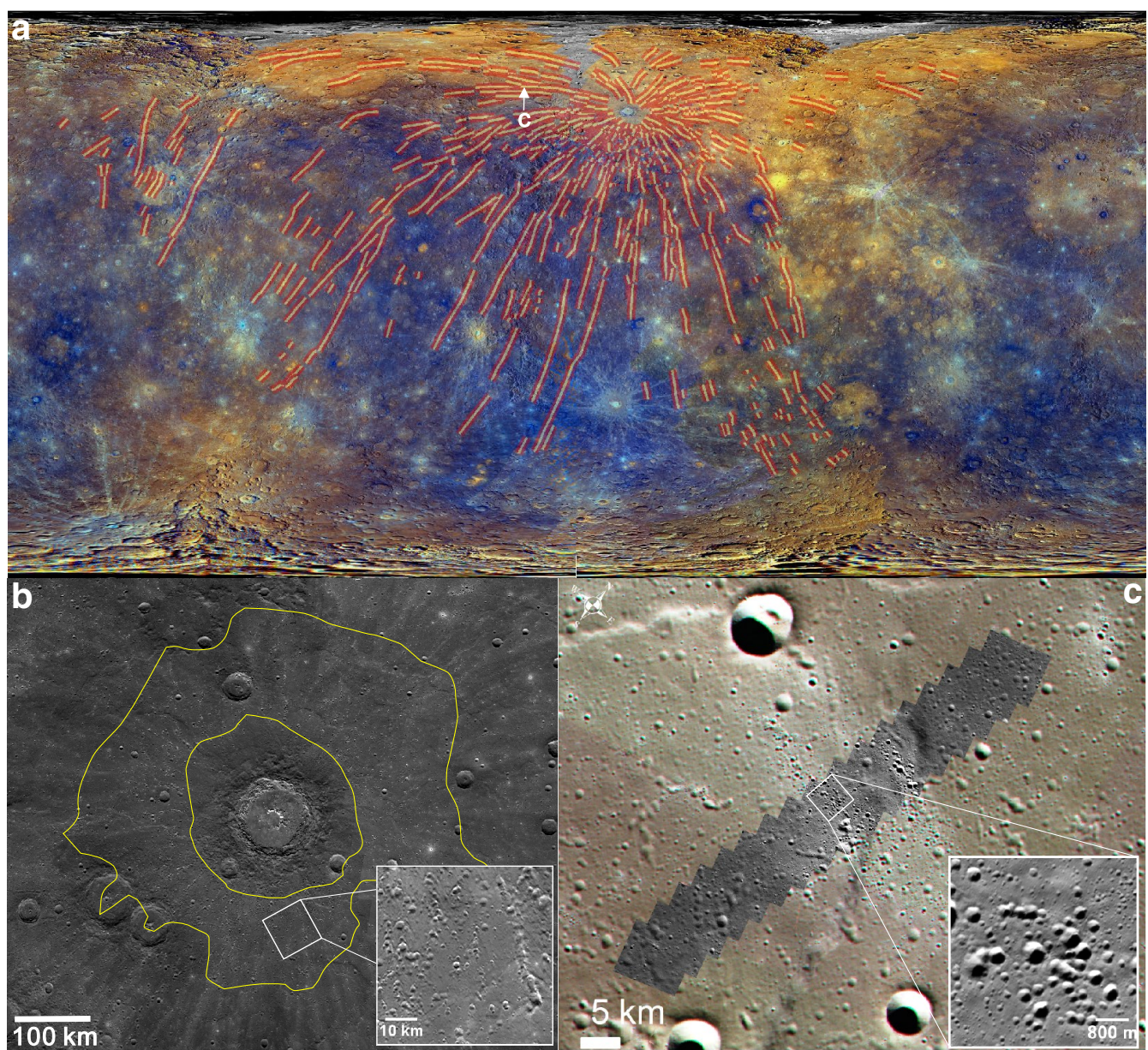

Fig. 2 a The near global distribution of impact rays of the Hokusai crater on Mercury. The base mosaic is an enhanced color mosaic of Mercury (3.74 km/pixel; equirectangular projection). The red, green, and blue channels are the second principal component, the first principal component, and the ratio of the $430 \mathrm{~nm} / 1000 \mathrm{~nm}$ filters, respectively, of the MDIS 8-band global mosaics (Xiao 2016). b Approximate outer boundaries of the continuous ejecta deposits and continuous secondaries facies of the Hokusai crater (yellow lines). The inset figures show an example of secondary crater clusters on the continuous secondaries facies. c Secondary crater chains within a distant ray segment of Hokusai (Xiao 2016). The location is marked in a. All the images are acquired by MESSENGER MDIS

Moon (e.g., Shoemaker 1962; Dundas and McEwen 2007; Xiao and Strom 2012), Mars (McEwen et al. 2005; Robbins and Hynek 2014), and Europa (Bierhaus et al. 2005); (2) Background secondaries are not abundant on planetary surfaces so they have negligible effect on crater statistics (e.g., Neukum and Ivanov 1994; Ivanov 2006; Werner et al. 2009; Xie et al. 2017); (3) Background secondaries do exist in populations of small impact craters, but the current crater chronology have integrated both primaries and background secondaries, so the effect of background secondaries has already been bracketed (Hartmann 2007; Hartmann and Daubar 2017). A full understanding of the spatial dispersion and SFD of impact fragments during the cratering process is required to investigate the heterogeneity of background secondaries in terms of diameter ranges and spatial locations, which may settle down the debate (Xiao 2016).

It is reasonable to assume that relative young surfaces are affected by potential background secondaries to a less degree and/or in a smaller diameter range than older surfaces, since fewer primaries could supply potential background secondaries on younger surfaces. On the Moon, Copernican is the latest stratigraphic era, which is represented by craters with observable optical impact rays (Wilhelms 1987). However, it has long been noticed that for a given Copernican-aged crater, the crater density across different places of the continuous ejecta deposits is variable (e.g., Shoemaker et al. 1968; Hartmann 1968). While it may be too 
farfetched to assume that background secondaries have dominated the small crater populations on the continuous ejecta deposits of these fresh impact craters, an interpretation for the observed crater density difference brought the long-ignored secondary crater population, self-secondary craters (i.e., self-secondaries) into sight (Shoemaker et al. 1968). Self-secondaries, also termed as auto-secondaries in some literatures (e.g., Plescia and Robinson 2011), are secondary craters formed both on the continuous ejecta deposits and interior of the parent craters. The widespread occurrence and possible significance of self-secondaries were not noticed until ultra-high resolution images with sub-meter pixel scales have recently been obtained by the Lunar Reconnaissance Orbiter Camera (LROC; Robinson et al. 2010) since the late 2009.

In this review, the history of the study of self-secondaries ("Discovery of self-secondaries" section), their occurrences on different planetary bodies ("Discovery of self-secondaries" and "Self-secondaries on the Moon" sections), possible formation mechanism ("Formation mechanism of self-secondaries on the Moon and terrestrial planets" section), importance to crater chronology
("The broad indication" section), and issues remained ("Left issues for a comprehensive understanding of selfsecondaries" section) are introduced.

\section{Cognitive process of self-secondaries Discovery of self-secondaries}

On 10 January 1968, the US Surveyor 7 spacecraft landed $\sim 30 \mathrm{~km}$ to the northern rim of the lunar Tycho crater (rim-to-rim diameter $D=85 \mathrm{~km} ; 43^{\circ} \mathrm{S}, 11^{\circ} \mathrm{W}$ ). The landing site is part of the continuous ejecta deposits of Tycho (Fig. 3a) that have a local thickness of $\sim 75 \mathrm{~m}$ estimated from the empirical scaling law of McGetchin et al. (1973), i.e., $h=0.14 R^{0.74}(r / R)^{-3.0}$; where $h$ is the ejecta deposit thickness, $r$ is the distance to the rim of the parent crater, and $R$ is the radius of the parent crater. Shoemaker et al. (1968) noticed that at this location, Tycho's continuous ejecta deposits have different surface textures and topographic roughness, and the crater density can be varied for as much as $\sim 10$ times at different ejecta facies within the diameter range of $\sim 7-70 \mathrm{~m}$ (Fig. 3a). The crater density difference was initially interpreted to be caused by late-stage volcanism on the rim of Tycho, and the

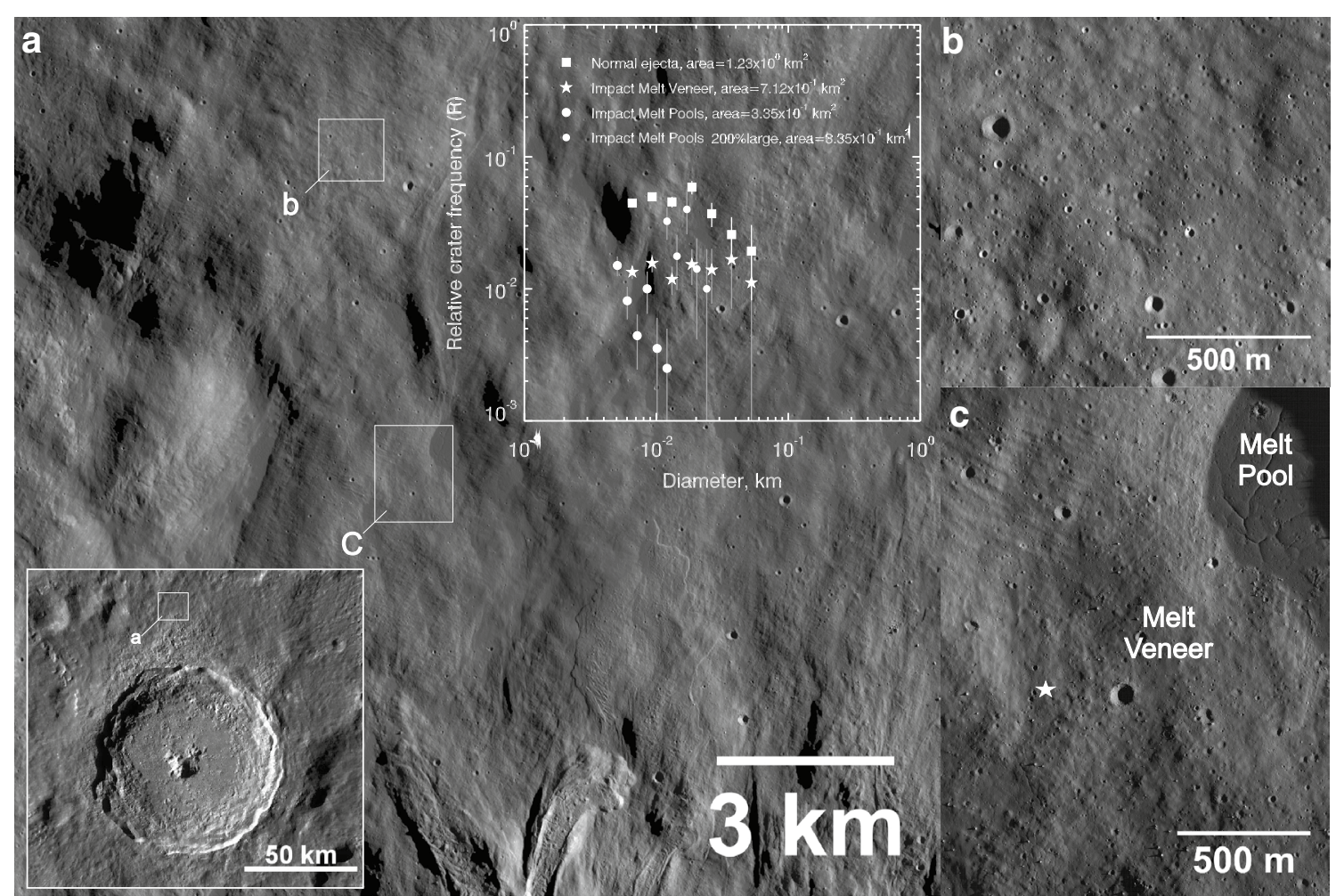

Fig. 3 The Surveyor 7 landing site (denoted as white star in c) on the northern ejecta deposits of Tycho. a Surface features of ejecta deposits around the landing site. The inset image shows the location of this frame. The inset plot shows the crater size-frequency distribution of craters on difference facies of the ejecta deposits. $\mathbf{b}$ Normal ejecta deposits to the north of the landing site show little modification by melt flows. c Melt pools and melt veneer near the landing site (Modified from Xiao and Werner (2015)) 
widespread melt flows and melt pools were interpreted to be lava flows (Strom and Fielder 1968).

Continuous ejecta deposits of newly formed impact craters are regarded as resurfaced units (Oberbeck et al. 1974), and previous crater record beneath the continuous ejecta deposits has been largely removed, at least for pre-existing craters that have rim-to-floor depths less than the local thickness of the continuous ejecta deposits. Crater populations accumulated on continuous ejecta deposits should be primaries and potential background secondaries produced by younger craters. For newly formed craters such as Tycho, background secondaries should not be abundant considering that few younger craters are large enough to produce the abundant small craters that have various preservation states (Fig. 3b). Therefore, Shoemaker et al. $(1968,1969)$ suggested that during the formation of the Tycho crater, some ejecta were launched with large ejection angles from the target surface, and they fell back and formed secondaries on the continuous ejecta deposits when the impact melt was still being emplaced.

After this first proposal, the possible existence of selfsecondaries on the continuous ejecta deposits of impact craters was basically neglected. A major reason is that high-resolution images that could resolve sub-hundredmeter diameter craters have been limited. The successful insertion of the Lunar Reconnaissance Orbiter (i.e., LRO) into the Moon's orbit in 2009 enabled the LROC narrow angle camera (i.e., NAC) to obtain high-resolution images as good as $\sim 0.5 \mathrm{~m} /$ pixel for lunar surfaces (Robinson et al. 2010). At the time of this writing, LRO is still operating, and LROC NAC has acquired images for over $90 \%$ of the entire Moon with a substantial portion been repeatedly imaged (e.g., Speyerer et al. 2016).

\section{Self-secondaries on the Moon}

Using high-resolution images obtained by LROC NAC, Plescia et al. (2010) observed crater density variations across the continuous ejecta deposits of the youngest lunar complex crater Giordano Bruno $\left(D=22 \mathrm{~km} ; 36^{\circ} \mathrm{S}\right.$, $\left.103^{\circ} \mathrm{E}\right)$. The self-secondaries scenario proposed by Shoemaker et al. $(1968,1969)$ was quoted to explain the different crater density observed (Plescia et al. 2010). This work officially brought the self-secondaries scenario back into the main stream, because the self-secondaries population could potentially invalidate both the theory and application reliability of the currently used crater chronology (Plescia 2012; “The broad indication" section).

LROC NAC provides the first observational evidence for the existence of self-secondaries. Many small impact craters on the continuous ejecta deposits of Copernicanaged craters have been embayed by later-arrived melt flows (Fig. 4a). Most of the small craters are less than

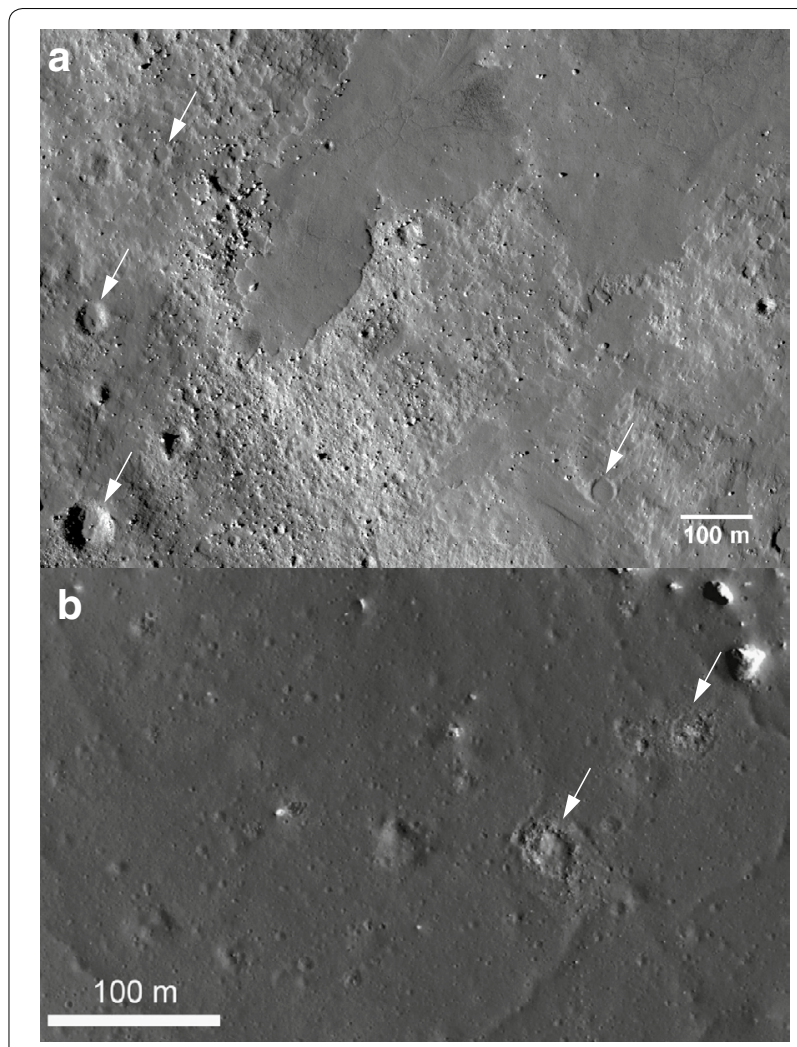

Fig. 4 a Self-secondaries on the southern continuous ejecta deposits of Giordano Bruno. Many small craters on the continuous ejecta deposits have been partly filled by melt flows. b Irregularly-shaped small craters on top of melt flows formed by the Lowell $\mathrm{H}$ crater (Plescia and Spudis 2014). North is toward the top. The base images are obtained by LROC NAC

$100 \mathrm{~m}$ in diameter and they have both circular rims and dispersed spatial distribution, which are similar to primaries. It has long been known that after the modification stage of the cratering process, melt flows on the continuous ejecta deposits could be sustained for a long time (e.g., Howard and Wilshire 1975; Osinski et al. 2011). The embayed small craters should have been formed soon after the emplacement of the continuous ejecta deposits, but before the subsequently arrived melt flows. Therefore, the narrow formation window proves that the embayed small craters are self-secondaries.

Besides Tycho (e.g., Xiao and Strom 2012; Zanetti et al. 2015, 2017) and Giordano Bruno (Plescia et al. 2010), now more Copernican-aged impact craters are revealed to have crater density differences on the continuous ejecta deposits, such as Aristarchus, Eudoxus, Jackson, King, and Copernicus (e.g., van der Bogert et al. 2010; Ashley et al. 2012; Zanetti et al. 2012; Hiesinger et al. 2012; Plescia 2012). The crater density difference is most frequently observed between melt pools and ejecta facies that have not been modified by subsequent melt flows (i.e., normal ejecta deposits formed after ballistic 
trajectory), as normal ejecta deposits have larger crater densities (e.g., van der Bogert et al. 2010; Zanetti et al. 2017). For example, Fig. 3 shows a recent revisit to the landing site of the Surveyor 7 mission (Xiao and Werner 2015; Xiao 2016), where the self-secondaries scenario was first proposed. Around the landing site, the different facies of Tycho's ejecta deposits (Shoemaker et al. 1969) can be classified into 3 types based on their surface textures: normal ejecta deposits that have minor modification by subsequent melt flows, melt veneer that cover normal ejecta deposits, and melt pools that are located at low-relief areas (Fig. 3c). The crater SFD on both the normal ejecta deposits and melt pools have differential power-law slopes (Crater Analysis Techniques Working Group 1979) of about -4, but the normal ejecta deposits have a larger crater density by a factor of up to 10 (Fig. 3). Assuming that craters $\sim 5-15 \mathrm{~m}$ diameter on the melt pool were all primaries that postdated Tycho, subtracting this population from that on the normal ejecta deposits would not substantially affect the density of the latter because of the large crater density difference. Moreover, the crater SFD on the melt veneer has a differential slope of about -3 , and the crater density is the same with the melt pool at $D=\sim 6 \mathrm{~m}$ and also the same with normal ejecta deposits at $D=\sim 50 \mathrm{~m}$ (Fig. 3). This is consistent with the fact that the melt veneer is a resurfaced unit, which has erased many small craters $(D<50 \mathrm{~m})$ on the original normal ejecta deposits. Therefore, the small crater population on the normal ejecta deposits should be dominated by self-secondaries, and most of them had been formed before the melt pools were collected at regional low-relief areas. Similar crater density differences and embayment relationship of different ejecta facies are observed on all the Copernican-aged craters, so in most of the cases (see "The target property scapegoat" section for an alternative interpretation), self-secondaries were employed to explain the observed crater density difference (e.g., Xiao and Strom 2012; Zanetti et al. 2012; Plescia and Robinson 2015; Zanetti et al. 2017).

Small craters on the melt pools of impact craters such as Giordano Bruno, Tycho, and King have different morphology with both primaries and typical secondaries (Plescia 2015), as they are much shallower, with irregularly shaped rims and small central mounds, and absence of well-developed ejecta (e.g., Fig. 4b). On the contrary, craters that are formed on the normal ejecta deposits do not have such morphological characteristics (e.g., Fig. 3b). The irregularly shaped craters formed on Tycho's melt pools have much smaller depth-diameter ratios $(\sim 0.06)$ than those formed on the normal ejecta deposits $(\sim 0.12)$, and their interior wall slopes are also much shallower $\left(\sim 9^{\circ}\right.$ versus $21^{\circ}$ on average; Plescia 2015). Plescia and Spudis (2014) interpreted these craters as self-secondaries (termed as palimpsests) that were formed after the emplacement, but before the solidification of the impact melt. This interpretation is supported by laboratory impact experiments into viscos targets (e.g., Bingham fluids such as cone mush), as the simulated craters have shallow depths, low rims, concentric rings, lobate margins, and central highs (Fink et al. 1981; Greely et al. 1980). It is also consistent with the fact that impact melt pools can have large solidification time for tens of thousands of years (e.g., Plescia and Spudis 2014). Therefore, it is likely that self-secondaries have been continuously accumulating on the continuous ejecta deposits, even after the melt pools have been ponded.

\section{Self-secondaries on the other planetary bodies}

The Hokusai crater on Mercury $\left(D=96 \mathrm{~km} ; 57.8^{\circ} \mathrm{N}\right.$, $16.8^{\circ} \mathrm{E}$ ) provides the conclusive evidence that self-secondaries dominate the continuous ejecta deposits of newly formed impact craters (Xiao et al. 2016). Highresolution images obtained by the Mercury Dual Imaging System (i.e., MDIS; Hawkins et al. 2007) onboard the MErcury Surface, Space ENviroment, GEochemistry, and Ranging (MESSENGER; Solomon et al. 2001) spacecraft reveal that Hokusai is the youngest crater of its size on Mercury (Xiao 2016). Hokusai exhibits a proto-peak-ring and quasi-layered ejecta deposits (Xiao and Komatsu 2013), which are unique compared with similar-sized fresh craters on Mercury. Both the crater floor and continuous ejecta deposits are largely covered by impact melt. MDIS NAC images reveal that craters larger than 100 in diameter are abundant on the continuous ejecta deposits, but the flat crater floor only contains a handful of impact craters (Xiao et al. 2016). The small craters are circular in shape and they do not occur in clusters or chains, and most of them are less than $300 \mathrm{~m}$ in diameter. Small primaries or distant secondaries from craters younger than Hokusai should have occurred on the crater floor and continuous ejecta deposits. This contrast in crater density suggests that most of the small craters on the continuous ejecta deposits are the self-secondaries formed by Hokusai, which were emplaced before the melt sheet on the crater floor had been solidified to certain depths (Xiao et al. 2016). Notably, the small crater population on the continuous ejecta deposits of Hokusai is emplaced on top of melt flows (i.e., equivalent to the melt veneer shown in Fig. 3a). Therefore, self-secondaries that were formed before the emplacement of melt flows may have been partly removed.

On Mars, mapping of craters on the continuous ejecta deposits of the Tooting crater $(D=28 \mathrm{~km}$; $\left.23.1^{\circ} \mathrm{N}, 207.1^{\circ} \mathrm{E}\right)$ also revealed the dominance by selfsecondaries (Boyce and Mounginis-Mark 2015). Tooting is one of the youngest complex craters on Mars 


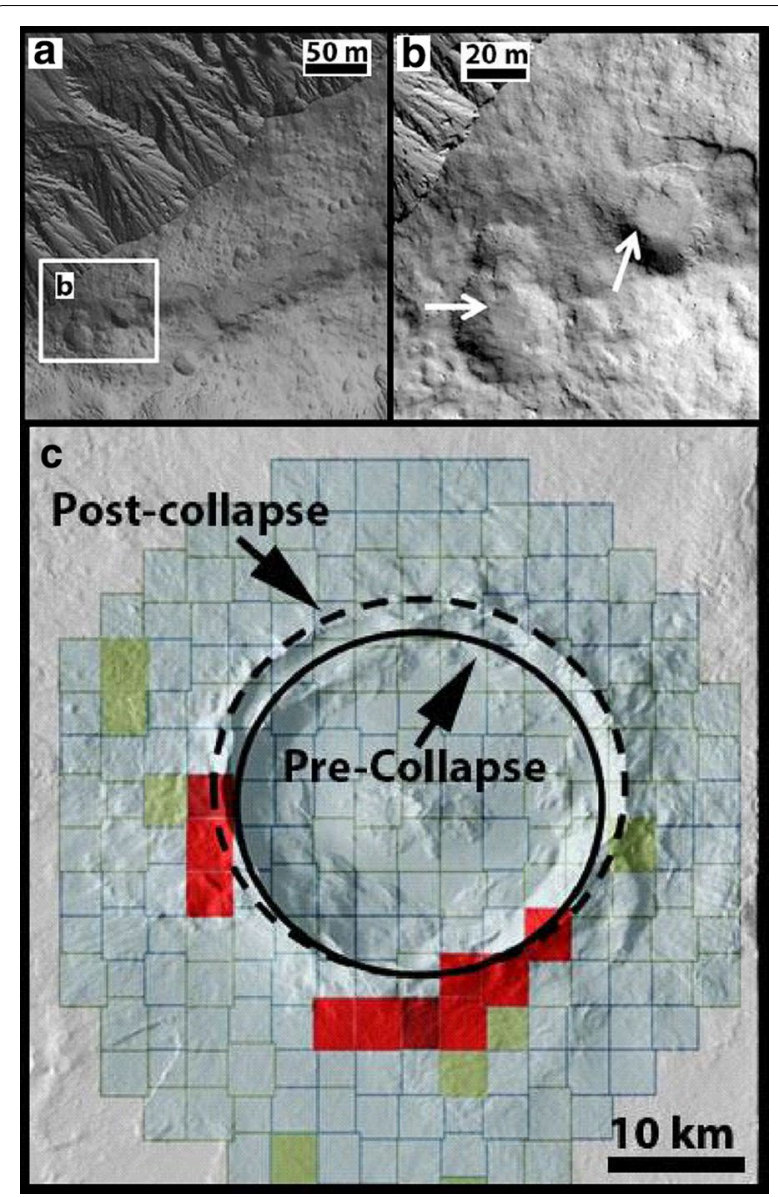

Fig. 5 Self-secondaries on the continuous ejecta deposits of the Tooting crater on Mars (modified from Boyce and Mounginis-Mark 2015). a The southeastern crater rim of Tooting shows the embayment relationship between self-secondaries and melt flows. b Some small craters on the continuous ejecta deposits are partly filled by melt flows (white arrows), and the location of this image is marked in a. c The spatial density of small craters on the continuous ejecta deposits of Tooting is not uniform, as the southern part has a higher crater density

that may be formed within the last 0.1 Myr (McEwen 2006), and primaries are barely seen on top of this crater. On the continuous ejecta deposits, embayment of small craters by impact melt flows suggests that the small craters are self-secondaries (Fig. 5a, b). Crater density differences are also observed on the continuous ejecta deposits, as the southern rim exhibits larger densities (Fig. 5c). Boyce and Mounginis-Mark (2015) suggested that the small craters on the continuous ejecta deposits are self-secondaries, and the northern crater rim has undergone larger amount of collapse so that part of the self-secondaries were destroyed. Notably, Schultz and Singer (1980) suggested that the large inventory of subsurface volatiles on Mars may have caused larger ejection angles, forming more circularly shaped secondaries within the continuous secondaries facies around some martian crater. Accounting for the enhanced crater collapse during the modification stage, the continuous secondaries facies of these craters are located closer to the crater rim, thus some of these secondaries are located within the occurrence area of self-secondaries. Strictly by definition, these secondaries are not self-secondaries.

On Saturn's midsize icy moon Rhea (surface gravity $\sim 0.26 \mathrm{~m} / \mathrm{s}^{2}$, rotation period $\sim 4.52$ Earth days), Schenk et al. (2017) recently recognized self-secondaries that are produced by the extremely fresh Inktomi crater $(D=48 \mathrm{~km})$. Inktomi is the youngest crater larger than $10 \mathrm{~km}$ in the Saturn system. High-resolution images show that nearly no crater is visible on the western crater floor or ejecta deposits, but there is a cluster of small craters on both the eastern crater floor and ejecta deposits. Unlike self-secondaries that are found on the Moon, Mercury and Mars, these small craters have identical morphology, spatial distribution, and SFD with typical secondaries. Schenk et al. (2017) suggested the small craters are the self-secondaries produced by Inktomi based on their asymmetric distribution and also no craters younger than Inktomi could supply possible distant secondaries.

Craters formed on bodies that have much faster rotation periods than the Moon and terrestrial planets could also form self-secondaries, although the trajectory of the ejecta that formed these secondaries and their emplacement sequence may not be the same with those on the Moon. Neesemann et al. (2016) found that the Coriolis force significantly affects the trajectory of impact ejecta and the spatial distribution of secondaries on 1Ceres (surface gravity $\sim 0.28 \mathrm{~m} / \mathrm{s}^{2}$; rotation period $\sim 9 \mathrm{~h}$ ). Instead of forming secondaries that are radially distributed in chains and clusters, the trajectory of impact fragments were redirected westward, and some impact ejecta could land on both the continuous ejecta deposits and floor of the parent crater. Such distribution patterns of self-secondaries might also be observed on the other fast rotation bodies, such as 2Pallas (surface gravity $\sim 0.21 \mathrm{~m} /$ $\mathrm{s}^{2}$; rotation period $\sim 7.8 \mathrm{~h}$ ) and 4 Vesta (surface gravity $\sim 0.25 \mathrm{~m} / \mathrm{s}^{2}$; rotation period $\sim 5.3 \mathrm{~h}$ ), although self-secondaries on these bodies have not been confirmed. On the other hand, the icy and gas giants in the outer solar system have abundant small satellites that have low surface gravities, e.g., Enceladus (surface gravity $\sim 0.113 \mathrm{~m} /$ $\mathrm{s}^{2}$ ) and Mimas (surface gravity $\sim 0.064 \mathrm{~m} / \mathrm{s}^{2}$ ). Little or no traditional secondary craters should be formed on these bodies, because the minimum velocity required to form secondaries have exceeded the escape velocities of these bodies (Bierhaus et al. 2012). However, most impact 
ejecta that have escaped the parent body would impact both the parent body and moons in adjacent orbits, forming sesquinaries. Sesquinaries are likely not formed in clusters, but will be spread across the surface, sometimes having hemispherical concentrations (Alvarellos et al. 2005, 2017). Therefore, when sesquinaries are formed on the continuous ejecta deposits and interior of a fresh crater, they can be mixed with the potential self-secondaries.

\section{Formation mechanism of self-secondaries on the Moon and terrestrial planets The target property scapegoat}

With the unambiguous observational evidence for both the existence of self-secondaries (e.g., Fig. 4) and their dominance in small crater populations on the continuous ejecta deposits of newly formed impact craters (e.g., the Hokusai case on Mercury), however, there are debates about whether or not self-secondaries are needed to explain the observed crater density differences on Copernican-aged lunar craters. Contemporaneous with the return of the self-secondaries scenario (Plescia et al. 2010), the long-ignored but poorly understood effect of target properties on the SFD of small impact craters were interpreted to be the cause for the larger crater density on normal ejecta deposits than melt pools (e.g., van der Bogert et al. 2010). According to this interpretation, different target properties (e.g., density, cohesion, porosity) can cause up to 2 times differences in crater rim-to-rim diameters for same-energy impactors, so that small craters formed on melt pools and normal ejecta deposits have both different SFD and densities (van der Bogert et al. 2017).

It is true that target properties must have affected the formation, thus the SFD of small impact craters, but target property differences are not the major reason for the observed crater density differences across continuous ejecta deposits. During the cratering process, excavation by small energy impacts is mainly halted by target strength (i.e., the strength-regime cratering process) and that by larger energy impacts is mainly controlled by gravity (i.e., the gravity-regime cratering process; Melosh 1989). On the Moon, depending on the effective strength of target materials, the transition from strength- to gravity-regime cratering process normally occurs for craters with final rim-to-rim diameter of $\sim 400 \mathrm{~m}$, and on Mars and Mercury, the transition diameter is $\sim 200 \mathrm{~m}$ (Melosh 1989). Most of the observed self-secondaries on the Moon, Mercury and Mars are formed within the gravityregime or the transition regime, so that target properties must have played an important role in the formation. van der Bogert et al. (2017) employed empirical cratering scaling laws that were derived from laboratory impact experiments to investigate the effect of target porosity and effective strength on the SFD of small impact craters. They suggested that while self-secondaries do exit, craters formed on the more competent and less porous melt pools are much smaller than those formed on the highly porous normal ejecta deposits, and this effect is the major contribution for the observed crater differences. For example, if same-projectiles could form $\sim 1.6$ times larger craters on normal ejecta than melt pools, the crater density difference between these two ejecta facies will be vanished. However, Fig. $3 \mathrm{c}$ shows that even enlarging craters on the normal ejecta deposits by a factor 2, the crater density difference between melt pools and normal ejecta still exists (see also similar analyses by Zanetti et al. 2017). More importantly, the actual properties of lunar materials are not precisely constrained at all (e.g., cohesion and porosity), and the scaling parameters used in the empirical scaling laws were uniformly for hard rocks (van der Bogert et al. 2017). Recent high-resolution numerical modeling for the formation of transient craters in the strength- and transition-regimes reveals that the scaling parameters are highly dependent on the target properties investigated, and modeling for the whole collapse stage is still ongoing (Prieur et al. 2017). Therefore, the detailed effect of target properties on the rim-to-rim diameter and SFD of small craters is still far from being settled.

A fundamental paradox exists in employing target property differences to explain the observed crater density differences between melt pools and normal ejecta. Plescia and Spudis (2014) believed that the irregularly shaped small craters on the melt pools are self-secondaries that were formed on the still-molten melt pools. However, the target property difference scenario regarded melt pools as competent rocks that have much larger cohesion and smaller porosity than normal ejecta (Williams and Pathare 2015; van der Bogert et al. 2017). Nevertheless, even assuming that craters formed on melt pools are 2 times smaller than those on normal ejecta deposits assuming same impactors, the large crater density difference still exists (Xiao 2016; Zanetti et al. 2017).

\section{Impact spallation}

The occurrence of self-secondaries on continuous ejecta deposits and the common embayment relationship between self-secondaries and melt flows suggest that the impact ejecta that formed self-secondaries must have larger ejection angles and longer trajectory time than ejecta that formed the continuous ejecta deposits. Depending on the energy of planetary impacts and target properties, materials are driven out of the final crater via five possible mechanisms (Melosh 1989): (1) impact jetting during the initial contact between the impactor and target launches superheated uppermost target and minor impactor materials (Kieffer 1977); the jetted 
materials have small launch angles with regard to the target surface $\left(<20^{\circ}\right)$ and large ejection velocities that may exceed several times the impact velocity (Kurosawa et al. 2015); so most of the jetted materials have escaped the target body if it is airless, and the rest are quickly quenched during the trajectory, forming impact glass; (2) vaporization of the projectile and target occurs during the early contact stage; the residual particle velocity and pressure gradient within the plume drives vapor expansion (Vickery 1986), and the micron-scale condensed droplets on Earth are formed by this process; (3) spallation caused by the interaction of shock waves and rarefaction waves launches target material from a shallow interference zone, where rarefaction waves arrive earlier than the peak of shock waves due to the nonzero rise time of the shock pulse; spall fragments launched by kilometer-scale lunar and Martian craters, together with acceleration by thermal expansion, can have velocities exceeding the escape velocity of the target body (Melosh 1984; Kurosawa et al. 2017); (4) the incompressible and subsonic excavation flows, which are initiated by shock waves and subsequently excited by rarefaction waves, are the major mechanism of excavating materials, and most of the excavated materials are deposited near the margin of the transient crater (Melosh 1989); (5) the collapse of the excavation cavity, intertwined with the formation of central peaks/rings, may push a small amount of mixtures of impact melt and clasts toward the crater exterior (Osinski et al. 2011).

Fragments launched during the early spallation process are the sources that formed self-secondaries on the Moon, Mercury and Mars (Xiao et al. 2016). Schenk et al. (2017) suggested that jetting during the early phase of the cratering process might have formed the self-secondaries on Rhea, but jetting occurs with low ejection angles and most of the jetted materials are melted (Kurosawa et al. 2015). Excavation flow is the major mechanism in the formation of continuous ejecta deposits, but excavation flows have gradually decreased velocities with larger launch distances from the impact site (e.g., Houson and Holsapple 2011), and laboratory oblique impact experiments show that ejection angles during the excavation stage vary by less than $\sim 15^{\circ}\left(\sim 35^{\circ}-50^{\circ}\right.$; Anderson et al. 2003). Therefore, larger trajectory time in excavation flows generally means larger ejection velocity, thus longer ballistic ranges. The later arrival of self-secondaries on top of continuous ejecta deposits indicate that self-secondaries cannot be launched by excavation flows. Accounting for the possible movement time of melt flows, on top of which self-secondaries are recognized (e.g., the Hokusai case), the trajectory time of fragments that formed self-secondaries are much larger than the combined time of crater excavation and modification (Xiao et al. 2016). The long trajectory time and the short trajectory distance requires that the ejecta that formed self-secondaries were launched early in the cratering process with both large ejection angles (up to $85^{\circ}$ regarding the target surface) and velocities (up to the escape velocity). Spallation provides the most probable explanation for these requirements, because fragments ejected during the early spallation stage have ejection velocities approaching the impact velocity that formed the parent crater (Melosh 1984), and near-vertical launch angles (Polanskey and Ahrens 1990). The observed selfsecondary crater populations on the Moon, Mars and Mercury are mostly less than $\sim 300 \mathrm{~m}$ in diameter, much smaller than secondaries on the continuous secondaries facies. This is consistent with the fact that spall fragments ejected early during the cratering process have large velocities but small sizes due to the thinner interference zone and larger residual elastic energies (Melosh 1985). Moreover, the large ejection angles of fragments that form self-secondaries can explain their circular morphology and scattered spatial distribution (Schultz and Gault 1985). Notably, buried detonations of nuclear and large chemical explosions are analogues of impact cratering, and abundant self-secondaries are also formed on the ejecta blanket of the Sedan crater (390 m diameter; 104 kT TNT; Carlson and Roberts 1963). Surface materials launched by spallation may be the source of Sedan's self-secondaries. However, gas expansion plays a fundamental role during the growth of explosion craters, so whether or not self-secondaries formed by detonations could be analog to those formed by impact cratering is questionable (van der Bogert et al. 2017).

Self-secondaries should be an inherent by-product of impact cratering processes that form complex craters on the Moon and terrestrial planets (Xiao et al. 2016). Spallation must have occurred during the cratering process (Melosh 1984), so that target materials launched early from spallation zones could land again on top of the other ejecta facies. If the spalled fragments have large enough strength and size, self-secondaries could be formed. The common occurrence of self-secondaries on the Moon, Mercury and Mars verifies this possibility ("Cognitive process of self-secondaries" section).

\section{Significance of self-secondaries on crater statistics The broad indication}

The dominance of self-secondaries on continuous ejecta deposits of newly formed impact craters possess strong threat to both the theoretical plausibility of the age dating technique using crater statistics and the practical reliability of using this technique to date individual craters. A basic tenant of crater statistics is that each crater is an independent random event. Self-secondaries are 
essentially formed simultaneously on continuous ejecta deposits, and they represent an extreme violation of this tenant. 4 of the 14 calibration sites that were used to build the lunar crater chronology function are the continuous ejecta blankets of Copernican-aged craters (Fig. 1c), and the Copernican-aged portion of the crater chronology function has been regarded as the best calibrated part. The crater SFD observed on the continuous ejecta deposits of the 4 craters were considered to be the production crater population (e.g., Neukum and Ivanov 1994). However, the presence of self-secondaries on continuous ejecta deposits has caused uncorrelated relationship between their sample ages and the observed crater densities, and the actual density of primaries formed on the continuous ejecta deposits should be lower. For example, Plescia and Robinson (2011) noticed that the crater density on the continuous ejecta deposits of Cone and North Ray is comparable, but the ages for the two craters are different by factor of 2 as revealed by the Apollo samples. Therefore, if assuming that the small crater populations on the continuous ejecta deposits of Tycho and younger craters are dominated by self-secondaries, Zanetti et al. (2017) suggest that the cratering rate on the Moon during the Copernican era may have been overestimated by factor of 4. On the other hand, ages of individual crater are usually derived by crater statistics on their continuous ejecta deposits. However, the existence of self-secondaries and their comparable morphology with primaries would cause the observed crater densities larger than those of the primary production populations. Although impact melt pools on continuous ejecta deposits of young craters may also have been bombarded by self-secondaries (Plescia and Spudis 2014), the crater density is much lower than that on the normal ejecta deposits. Therefore, it has been suggested that crater statistics on melt pools provide a closer approximation of the actual production population (Plescia and Robinson 2011, 2015; Plescia 2012; Zanetti et al. 2017).

\section{Left issues for a comprehensive understanding of self-secondaries}

There are always more unknowns than what we think we already know in any scientific fields, the same is especially true for the self-secondaries issue. While the broad indication for the importance of self-secondaries on crater statistics is obvious, fully unlocking the effects needs more systematic work. For example, what is the occurrence of self-secondaries on various ejecta facies? This question is related to the possible formation time of selfsecondaries populations. Are there SFD of newly formed self-secondaries idential for craters with different sizes and/or ages? This problem would determine whether or not the effect of self-secondaries on crater statistics could be removed by applying a representative crater SFD. Several of such critical issues are discussed below.

\section{Spatial distribution and SFD of self-secondaries around newly formed craters}

The interpretation that target material differences between melt pools and normal ejecta deposits may be the major reason for the observed crater density differences is mainly for craters with ages larger than Tycho, because primaries and possible background secondaries must have been continuously accumulated on these craters. The continuous ejecta deposits of newly formed impact craters have best recorded the self-secondaries crater population, such as the Hokusai crater on Mercury (Xiao et al. 2016), Giordano Bruno crater on the Moon (Williams and Pathare 2015), and Tooting crater on Mars (Boyce and Mounginis-Mark 2015). Self-secondaries on melt flows around the Hokusai crater do not have differentiable SFD difference at different azimuths of the crater rim, although the density of self-secondaries in terms of the $\mathrm{N}(D \geq 0.1 \mathrm{~km})$ value (i.e., the number of craters equal with or larger than $0.1 \mathrm{~km}$ in diameter per million square kilometers) seems to have been enhanced at the uprange by a maximum factor of $\sim 2$ (Xiao et al. 2016). However, the relatively low resolution of MESSENGER MDIS NAC images $(\sim 20 \mathrm{~m} /$ pixel $)$ prohibits reliable recognition of self-secondaries that are less than $100 \mathrm{~m}$ in diameter. The SFD of self-secondaries that are formed at different azimuths of Giordano Bruno has not been investigated. Although Plescia et al. (2010) noticed that crater populations at different distances from the crater rim of Giordano Bruno have various densities in terms of the $\mathrm{N}(D \geq 20 \mathrm{~m})$ and $\mathrm{N}(D \geq 40 \mathrm{~m})$ values, the SFD of small craters on the continuous ejecta deposits does not show radial variations (Xiao and Strom 2012). After the distribution pattern of self-secondaries around different-sized fresh impact craters is revealed, the possible production density of self-secondaries can be determined, thus the effect of self-secondaries could be removed from crater chronologies.

\section{Occurrence of self-secondaries on various ejecta facies of impact craters}

Self-secondaries formed on normal ejecta deposits have been unambiguously confirmed, but their occurrence on different-sized melt pools needs to be confirmed. The morphology and geometry of many small craters on the melt pools of Tycho are consistent with being self-secondaries, but this hypothesis needs to be tested by comparing the possible trajectory time of spall fragments, the movement time of melt flows considering the initial outward momentum, and the cooling time of melt pools (Xiao et al. 2016). The occurrence and possible 
dominance of self-secondaries on melt pools would reveal the emplacement sequence of self-secondaries in the frame of the formation of continuous ejecta deposits. On the other hand, it has been frequently quoted that self-secondaries that are located at larger distances from the parent crater rim have larger crater densities (Zanetti et al. 2015, 2017). This possible trend is established after studying the whole crater populations on the continuous ejecta deposits of Tycho and Aristarchus. However, it should be noted that continuous ejecta deposits of complex craters are composed of different ejecta facies, as impact melt flows that postdate the modification stage have altered the local density of self-secondaries to different degrees (e.g., Fig. 3). Therefore, it is necessary to evaluate the local geological context before interpreting the observed crater density differences.

\section{Evolution of self-secondary crater population with time}

Subsequent to the near simultaneous formation of selfsecondaries, primaries and possible background secondaries accumulate on the continuous ejecta deposits, enlarging the crater density. After certain time, the low density of self-secondaries would not contribute significantly to the local crater population, so that the effect of self-secondaries will gradually diminish with time (Xiao et al. 2016). However, the transition time for the relative abundance of self-secondaries and younger crater populations has not been revealed yet. This problem is especially important for melt pools, because they are regarded to be less affected by self-secondaries. The transition time is intertwined with crater degradation, since saturation equilibrium is approached from small crater diameters. It has been suggested that populations of small craters on the normal ejecta deposits of Tycho, which are dominated by self-secondaries have achieved the equilibrium state at $D<\sim 15 \mathrm{~m}$ in diameter, but crater populations on the melt pools of Tycho have not been in equilibrium at $D \geq 5$ m (Shoemaker et al. 1969; Xiao 2016). Likewise, crater populations on the impact melt pools of the King crater is in equilibrium at $D \leq 40-50 \mathrm{~m}$ (Ashley et al. 2012), those on surfaces $\sim 220$ Myr old are in equilibrium at $D \leq 20 \mathrm{~m}$ (Hiesinger et al. 2012), and those on melt pools of the Copernicus crater are in equilibrium at $D \leq \sim 100 \mathrm{~m}$ (Xiao and Werner 2015). Therefore, both the gradual accumulation of younger crater populations and crater degradation should be considered when studying the evolution of crater populations on continuous ejecta deposits.

\section{Possible contribution of background secondaries as constrained by self-secondaries}

The possible dominance of background secondaries in populations of small craters has been a persistent difficulty and debate. On continuous ejecta deposits of impact craters, self-secondaries, primaries and potential background secondaries are theoretically coexisted. Within the diameter range of self-secondaries, the production SFD of primaries on continuous ejecta deposits can be roughly constrained based on their samples ages and the impact flux estimated from newly formed craters (e.g., Daubar et al. 2013; Speyerer et al. 2016). If the production SFD of self-secondaries at different azimuths and radial distances of the parent crater rim could be represented by a representative production SFD, or it is more or less stable as revealed by the Hokusai (Xiao et al. 2016) and Giordano Bruno (Xiao and Strom 2012) cases, the possible SFD of background secondaries can be determined by subtracting the SFD of primaries and self-secondaries from that of the observed crater population.

\section{Conclusion}

Self-secondaries are secondary craters that are formed on both the continuous ejecta deposits and interior of the parent crater. After the first proposal in 1968, this crater population has not been studied in detail until global high-resolutions images recently obtained for the Moon are available. So far, self-secondaries have been confirmed on various-sized Copernican-aged craters on the Moon, and their common existence has also been confirmed on Mercury, Mars and some icy satellites. Near vertically launched ejecta by spallation are the source of self-secondaries, and self-secondaries are an inherent by product of impact cratering that form complex craters on planetary bodies. A direct manifestation of self-secondaries is the different crater density across continuous ejecta deposits, as melt pools have much lower crater density than ejecta deposits that have not been modified by melt flows. While target property difference must have affected the size-frequency distribution of small impact craters, this effect is not the major reason for the observed crater density differences. Self-secondaries have significantly affected the age-determination technique using crater statistics, especially for recently formed impact crater, because self-secondaries have caused larger densities on continuous ejecta deposits compared to the actual density of primary craters. This effect brings uncertainties to the widely used crater chronology. The spatial and size-frequency distributions of self-secondaries at different ejecta facies of different-sized craters have not been systematically investigated, which are critical questions to be resolved to fully unlock the significance of self-secondaries.

Abbreviations

SFD: size-frequency distribution; PF: production function; CF: chronology function; Secondaries: secondary craters; Self-secondaries: self-secondary 
craters; Primaries: primary craters; LRO: lunar reconnaissance orbiter; LROC: lunar reconnaissance orbiter camera; MESSENGER: MErcury Surface, Space ENvironment, GEochemistry, and Ranging; NAC: narrow angle camera; WAC: wide angle camera.

\section{Authors' contributions}

ZX is responsible for all the parts involved in this manuscript. The author read and approved the final manuscript.

\section{Author details}

1 Planetary Science Institute, School of Earth Sciences, China University of Geosciences (Wuhan), \#388 Lumo Road, Hongshan District, Wuhan 430074, Hubei, China. ${ }^{2}$ Space Science Institute, Macau University of Science and Technology, Taipei, Macau, China.

\section{Acknowledgements}

The president of the Planetary Sciences Section of AOGS, Professor Varun Sheel, the Vice President, Professor Nori Namiki, and the editor-in-chief of Geoscience Letters Professor Kenji Stake are acknowledged for their support and encouragement during the preparation for the manuscript. Comments and suggestions from the two anonymous reviewers are acknowledged. Professor Jun Cui from the Sun Yat-sen University is thanked for introducing me to join the AOGS community.

\section{Competing interests}

The author declares no competing interests.

\section{Availability of data and materials}

The data reported in this review paper are from published literatures.

\section{Consent for publication}

Not applicable.

Ethics approval and consent to participate

Not applicable.

\section{Funding}

This study is supported by National Natural Science Foundation of China (Nos. 41403053 and 41773063) and the Fundamental Research Funds for the Central Universities, China University of Geosciences (Wuhan) (No. CUGL150405).

\section{Publisher's Note}

Springer Nature remains neutral with regard to jurisdictional claims in published maps and institutional affiliations.

Received: 10 December 2017 Accepted: 29 June 2018

Published online: 09 July 2018

\section{References}

Alvarellos JL, Zahnle KJ, Dobrovolskis AR, Hamill P (2005) Fates of satellite ejecta in the saturn system. Icarus 178:104-123. https://doi.org/10.1016/j. icarus.2005.04.017

Alvarellos JL, Dobrovolskis AR, Zahnle KJ, Hamill P. Dones L, Robbins S (2017) Fates of satellite ejecta in the saturn system, II. Icarus 284:70-89. https:// doi.org/10.1016/j.icarus.2016.10.028

Anderson JLB, Schultz PH, Heineck JT (2003) Asymmetry of ejecta flow during oblique impacts using three dimensional particle image velocimetry. J Geophys Res 108(E8):5094. https://doi.org/10.1029/2003JE002075

Ashley JW, Robinson MS, Hawke BR, van der Bogert CH, Hiesinger H, Sato H, Speyerer EJ, Enns AC, Wagner RV, Young KE, Burns KN (2012) Geology of the King crater region: new insights into impact melt dynamics on the Moon. J Geophys Res. https://doi.org/10.1029/2011je003990

Bierhaus EB, Chapman CR, Merline WJ (2005) Secondary craters on Europa and implications for cratered surfaces. Nature 437:1125-1127. https://doi. org/10.1038/nature04069

Bierhaus EB, Dones ML, Alvarellos JL, Zahnle K (2012) The role of ejecta in the small crater populations on the mid-sized Saturnian satellites. Icarus 218:602-621. https://doi.org/10.1016/j.icarus.2011.12.011
Boyce JM, Mounginis-Mark PJ (2015) Anomalous areas of high crater density on the rim of the Martian crater tooting. In: Abstracts of the workshop on issues in crater studies and the dating of planetary surfaces, Laurel, 19-22 May 2015

Carlson RH, Roberts WA (1963) Project Sedan: Mass distribution and throw out studies. US Atomic Energy Commission Report PNE-217F. p. 144

Crater Analysis Techniques Working Group (1979) Standard techniques for presentation and analysis of crater size frequency data. Icarus 37:467-474. https://doi.org/10.1016/0019-1035(79)90009-5

Daubar IJ, McEwen AS, Byrne S, Kennedy MR, Ivanov B (2013) The current Martian cratering rate. Icarus 225:506-516. https://doi.org/10.1016/j.icaru s.2013.04.009

Dundas CM, McEwen AS (2007) Rays and secondary craters of Tycho. Icarus 186:31-40. https://doi.org/10.1016/j.icarus.2006.08.011

Fassett Cl (2016) Analysis of impact crater populations and the geochronology of planetary surfaces in the inner solar system. J Geophys Res Planets 121:1900-1926. https://doi.org/10.1002/2016JE005094

Fink JH, Greely R, Gault DE (1981) Impact cratering experiments in Bingham materials and the morphology of craters on Mars and Ganymede. In: Paper presented at the 12th lunar planetary science conference, Houston, 16-20 March 1981

French BM (1998) Trace of catastrophe: a handbook of shock-metamorphic effects in terrestrial meteorite impact structures. Houston, Texas

Greely R, Fink J, Snyder DB, Gault DE, Guest JE, Schultz PH (1980) Impact cratering in viscous targets: laboratory experiments. In: Paper presented at the 11 th lunar planetary science conference, Houston, 17-21 March 1980

Hartmann WK (1965) Terrestrial and lunar flux of large meteorites in the last two billion years. Icarus 4:157-165. https://doi.org/10.1016/00191035(65)90057-6

Hartmann WK (1968) Lunar crater counts. VI: the young craters Tycho, Aristarchus, and Copernicus. Commun Lunar Planetary Lab 8:145-156

Hartmann WK (1977) Relative crater production rates on planets. Icarus 31:260-276. https://doi.org/10.1016/0019-1035(77)90037-9

Hartmann WK (2007) Martian cratering 9. Toward resolution of the controversy about small craters. Icarus 189:274-278. https://doi.org/10.1016/j.icaru s.2007.02.011

Hartmann WK, Daubar IJ (2017) Martian cratering 11. Utilizing decameter scale crater populations to study Martian history. Meteorit Planet Sci 52:493-510. https://doi.org/10.1111/maps.12807

Hawkins SE, Boldt JD, Darlington EH, Espiritu R, Gold RE, Gotwols B, Gery MP, Hash CD, Hayes JR, Jaskulet SE, Kardian CJ, Keller MR, Malaret ER, Murchie SL, Murphy PK, Peacock K, Prockter LM, Reiter RA, Robinson MS, Schaefer ED, Shelton RG, Sterner RE, Taylor HW, Watters TR, Williams BD (2007) The mercury dual imaging system on the MESSENGER spacecraft. Space Sci Rev 131:247-338. https://doi.org/10.1007/s11214-007-9266-3

Hiesinger $\mathrm{H}$, van der Bogert $\mathrm{CH}$, Pasckert JH, Funcke L, Giacomini L, Ostrach LR, Robinson MS (2012) How old are young lunar craters? J Geophys Res Planets. https://doi.org/10.1029/2011je003935

Hirata N, Nakamura A (2006) Secondary craters of Tycho: size-frequency distributions and estimated fragment size-velocity relationships. J Geophys Res. https://doi.org/10.1029/2005JE002484

Houson KR, Holsapple KA (2011) Ejecta from impact craters. Icarus 211:856875. https://doi.org/10.1016/j.icarus.2010.09.017

Howard KA, Wilshire HG (1975) Flows of impact melt at lunar craters. J Res US Geol Surv 3:237-251

Ivanov BA (2006) Earth/Moon impact rate comparison: searching constraints for lunar secondary/primary cratering proportion. Icarus 183:504-507. https://doi.org/10.1016/j.icarus.2006.04.004

Kieffer SW (1977) Impact conditions required for formation of melt by jetting in silicates. In: Roddy DJ, Pepin RO, Merrill RB (eds) Impact and explosion cratering. Pergamon Press, New York

Kurosawa K, Nagaoka Y, Senshu H, Wada K, Hasegawa S, Sugita S, Matsui T (2015) Dynamics of hypervelocity jetting during oblique impacts of spherical projectiles investigated via ultrafast imaging. J Geophys Res Planets 120:1237-1251. https://doi.org/10.1002/2014JE004730

Kurosawa K, Okamoto T, Genda H (2017) Hydrocode modeling of the spallation process during hypervelocity impacts: implications for the ejection of Martian meteorites. Icarus. https://doi.org/10.1016/j.icarus.2017.09.015

McEwen AS (2006) Cratering age considerations for young terranes in the inner solar system. In: Abstracts of the workshop on surface ages and histories, Lunar and Planetary Institute, Houston, 23-23 May 2006 
McEwen AS, Bierhaus EB (2006) The importance of secondary cratering to age constraints on planetary surfaces. Ann Rev Earth Planetary Sci 34:535-567. https://doi.org/10.1146/annurev.earth.34.031405.125018

McEwen AS, Preblich BS, Turtle EP, Artemieva NA, Golombek MP, Hurst M, Kirk RL, Burr DM, Christensen PR (2005) The rayed crater Zunil and interpretations of small impact craters on mars. Icarus 176:351-381. https://doi. org/10.1016/j.icarus.2005.02.009

Melosh HJ (1984) Impact ejection, spallation, and the origin of meteorites. Icarus 59:234-260. https://doi.org/10.1016/0019-1035(84)90026-5

Melosh HJ (1985) Ejection of rock fragments from planetary bodies. Geology 13:144-148. https://doi.org/10.1130/0091-7613(1985)13<144:EORFF $\mathrm{P}>2.0 . \mathrm{CO} ; 2$

Melosh HJ (1989) Impact cratering: a geologic process. Oxford University, NewYork

Neesemann A, Kneissl T, Schmedemann T, Walter SHG, Michael GG, van Gasselt S, Hiesinger H, Jaumann R, Raymond C, Russell CT (2016). Size-frequency distributions of km to sub-km sized impact craters on Ceres. In: Abstracts of 47th lunar and planetary science conference, Houston, 21-25 March 2016

Neukum G (1983) Meteoriten bombardement and datierung planetarer oberfluchen. Ludwig Maximilianis University, Münche

Neukum G, Ivanov BA (1994) Crater size distributions and impact probabilities on earth from lunar, terrestrial planet and asteroid cratering data. In: Gehrels T, Tucson T (eds) Hazards due to comets and asteroids. The University of Arizona Press, Arizona

Neukum G, König B, Arkani-Hamed J (1975) A study of lunar impact crater sizedistributions. Moon 12:201-229

Neukum G, Ivanov BA, Hartmann WK (2001) Cratering records in the inner solar system in relation to the lunar reference system. Solar Sys Rev 96:55-86. https://doi.org/10.1007/978-94-017-1035-0_3

Oberbeck VR, Morrison RH (1974) Laboratory simulation of the herring bone pattern associated with lunar secondary crater chains. Moon 9:415-455

Oberbeck VR, Hörz F, Morrison RH, Quaide WL, Gault DE (1974) Smooth plains and continuous deposits of craters and basins. Paper presented at 5 th lunar science conference, Houston, 18-22 March 1974

Osinski GR, Tornabene L, Grieve RA (2011) Impact ejecta emplacement on terrestrial planets. Earth Planet Sci Lett 310(3):167-181. https://doi. org/10.1016/j.epsl.2011.08.012

Plescia JB (2012) Uncertainties in the < 3 Ga lunar impact cratering chronology. In: Abstracts of 43rd lunar and planetary science conference, Houston, 19-23 March 2012

Plescia JB (2015) Lunar crater forms on melt sheets-origins and implications for self-secondary cratering and chronology. In: Abstracts of 46th lunar and planetary science conference, Houston, 16-20 March 2015

Plescia JB, Robinson MS (2011) New constraints on the absolute lunar crater chronology. In: Abstracts of 42nd lunar and planetary science conference, Houston, 7-11 March 2011

Plescia JB, Robinson MS (2015) Lunar self-secondary cratering: implications for cratering and chronology. In: Abstracts of 46th lunar and planetary science conference, Houston, 16-20 March 2015

Plescia JB, Spudis PD (2014) Impact melt flows at Lowell crater. Planet Space Sci 103:219-227. https://doi.org/10.1016/j.pss.2014.08.003

Plescia JB, Robinson MS, Paige DA (2010) Giordano Bruno: the young and the restless. In: Abstracts of 41 st lunar and planetary science conference, Houston, 1-5 March 2010

Polanskey CA, Ahrens TJ (1990) Impact spallation experiments: fracture patterns and spall velocities. Icarus 87:140-155. https://doi. org/10.1016/0019-1035(90)90025-5

Prieur NC, Rolf T, Luther R, Wünnemann K, Xiao Z, Werner SC (2017) The effect of target properties on transient crater scaling for simple craters. J Geophys Res Planets 122:1704-1726. https://doi.org/10.1002/2017JE005283

Robbins SJ, Hynek BM (2014) The secondary crater population of mars. Earth Planet Sci Lett 400:66-76. https://doi.org/10.1016/j.epsl.2014.05.005

Robinson MS, Brylow SM, Tschimmel M, Humm D, Lawrence SJ, Thomas PC, Denevi BW, BowmanCisneros E, Zerr J, Ravine MA, Caplinger MA Ghaemi FT, Schaffner JA, Malin MC, Mahanti P, Bartels A, Anderson J, Tran TN, Eliason EM, McEwen AS, Turtle E, Jolliff BL, Hiesinger H (2010) Lunar reconnaissance orbiter camera (LROC) instrument overview. Space Sci Rev 150:81-124. https://doi.org/10.1007/s11214-010-9634-2

Robinson MS, Boyd AK, Denevi BW, Lawrence SJ, McEwen AS, Moser DE, Povilaitis RZ, Stelling RW, Suggs RM, Thompson SD, Wagner RV (2015) New crater on the moon and a swarm of secondaries. Icarus 252:229-235. https://doi.org/10.1016/j.icarus.2015.01.019

Schenk P, Hoogenboom T, Kirchoff M (2017) Auto secondaries on a midsize icy moon: bright rayed crater Inktomi (Rhea). In: Abstracts of 48th lunar and planetary science conference, The Woodlands, 20-24 March 2017

Schultz PH, Gault DE (1985) Clustered impacts: experiments and implications. Geophys Res 90:3701-3732. https://doi.org/10.1029/JB090iB05p03701

Schultz P, Singer J (1980) A comparison of secondary craters on the moon, mercury, and mars. In: Paper presented at 11 th lunar and planetary science conference, Houston, 17-21 March 1980

Shoemaker EM (1962) Interpretation of lunar craters. In: Kopal Z (ed) Physics and astronomy of the moon. Academic Press, New York

Shoemaker EM, Batson RM, Holt HE, Morris EC, Rennilson JJ, Whitaker EA (1968) Television observations from surveyor VII, in surveyor VII mission report, part II, science results. Natl Aeronautics Space Adm Tech Rep. 32-126A:9-76

Shoemaker EM, Batson RM, Holt HE, Morris EC, Rennilson JJ, Whitaker EA (1969) Observations of the lunar regolith and the earth from the television camera on surveyor 7. J Geophys Res 74:6081-6119. https://doi.org/10.1029/ JB074i025p06081

Solomon SC, McNutt RL Jr, Gold RE, Acuna MH, Baker DN, Boynton WV, Chapman CR, Cheng AF, Gloeckler G, Head JW, Krimigis SM, McClintock WE, Murchie SL, Peale SJ, Phillips RJ, Robinson MS, Slavin JA, Smith DE, Strom RG, Trombka Jl, Zuber MT (2001) The MESSENGER mission to Mercury: Scientific Objectives And Implementation. Planet Space Sci 49:1445-1465. https://doi.org/10.1016/S0032-0633(01)00085-X

Speyerer EJ, Povilaitis RZ, Robinson MS, Thomas PC, Wagner RV (2016) Quantifying crater production and regolith overturn on the moon with temporal imaging. Nature 538:215-218. https://doi.org/10.1038/nature19829

Stöffler D, Ryder G, Ivanov BA, Artemieva NA, Cintala MJ, Grieve RAF (2006) Cratering history and lunar chronology. Rev Miner Geochem 60:519-596. https://doi.org/10.2138/rmg.2006.60.05

Strom RG, Fielder G (1968) The multiphase development of the lunar crater tycho. Nature 217:611-615. https://doi.org/10.1038/217611a0

Strom RG, Malhotra R, Ito T, Yoshida F, Kring DA (2005) The origin of planetary impactors in the inner solar system. Science 309:1847-1850. https://doi. org/10.1126/science.1113544

Strom RG, Banks ME, Chapman CR, Fassett Cl, Forde JA, Head JW, Merline MJ, Prockter LM, Solomon SC (2011) Mercury crater statistics from MESSENGER flybys: implications for stratigraphy and resurfacing history. Planet Space Sci 59:1960-1967. https://doi.org/10.1016/j.pss.2011.03.018

Strom RG, Malhotra R, Xiao Z, Ito T, Yoshida F, Ostrach LR (2015) The inner solar system cratering record and the evolution of impactor populations. Res Astron Astrophys 15(3):407-434. https://doi. org/10.1088/1674.4527/15/3/009

van der Bogert $\mathrm{CH}$, Hiesinger $\mathrm{H}, \mathrm{McE}$ wen AS, Dundas $\mathrm{C}$, Bray $\mathrm{V}$, Robinson MS, Plescia JB, Reiss D, Klemm K, the LROC Team (2010) Discrepancies between crater size-frequency distributions on ejecta and impact melt pools at lunar craters: an effect of differing target properties? In: Abstracts of 41st lunar and planetary science conference, Houston, 1-5 March 2010

van der Bogert $\mathrm{CH}$, Hiesinger $\mathrm{H}$, Dundas $\mathrm{CM}$, Kruger T, McEwen AS, Zanetti M, Robinson MS (2017) Origin of discrepancies between crater sizefrequency distributions of coeval lunar geologic units via target property contrasts. Icarus 298:49-63. https://doi.org/10.1016/j.icarus.2016.11.040

Vickery AM (1986) Effect of an impact-generated gas cloud on the acceleration of solid ejecta. J Geophys Res 91:14139-14160. https://doi. org/10.1029/JB091iB14p14139

Werner SC, Ivanov BA, Neukum G (2009) Theoretical analysis of secondary cratering on Mars and an image-based study on the cerberus plains. Icarus 200:406-417. https://doi.org/10.1016/j.icarus.2008.10.011

Wilhelms DE (1987) The geologic history of the moon. US Geol Surv Prof Pap. 1348:302

Williams JP, Pathare AV (2015) Challenges using small craters for dating planetary surfaces. In: Abstracts of the workshop on issues in crater studies and the dating of planetary surfaces, Laurel, 19-22 May 2015

Williams JP, Pathare AV, Aharonson O (2014) The production of small primary craters on mars and the moon. Icarus 235:23-36. https://doi. org/10.1016/j.icarus.2014.03.011

Williams J, van der Bogert CH, Pathare AV, Michael GG, Kirchoff MR, Hiesinger $H$ (2017) Dating very young planetary surfaces from crater statistics: 
a review of issues and challenges. Meteorit Planet Sci. https://doi. org/10.1111/maps.12924

Xiao Z (2016) Size-frequency distribution of different secondary crater populations: 1. Equilibrium caused by secondary impacts. J Geophys Res Planets 121:2404-2425. https://doi.org/10.1002/2016JE005139

Xiao Z, Komatsu G (2013) Impact craters with ejecta flows and central pits on mercury. Planet Space Sci 82:62-78. https://doi.org/10.1016/j. pss.2013.03.015

Xiao Z, Strom RG (2012) Problems determining relative and absolute ages using the small crater population. Icarus 220:254-267. https://doi. org/10.1016/j.icarus.2012.05.012

Xiao Z, Werner SC (2015) Size-frequency distribution of crater populations in equilibrium on the moon. J Geophys Res Planets 120:2277-2292. https:// doi.org/10.1002/2015JE004860

Xiao Z, Strom RG, Chapman CR, Head JW, Klimczak C, Ostrach LR, Helbert J, D'Incecco P (2014) Comparisons of fresh complex impact craters on mercury and the moon: implications for controlling factors in impact excavation processes. Icarus 228:260-275. https://doi.org/10.1016/j.icaru s.2013.10.002

Xiao Z, Prieur NC, Werner SC (2016) The self secondary crater population of the Hokusai crater on mercury. Geophys Res Lett 43:7424-7432. https://doi. org/10.1002/2016GL069868
Xie M, Zhu MH, Xiao Z, Wu Y, Xu A (2017) Effect of topography degradation on crater size-frequency distributions: implications for populations of small craters and age dating. Geophys Res Lett 44:10171-10179. https://doi. org/10.1002/2017GL075298

Zanetti M, Jolliff B, van der Bogert CH, Hiesinger H (2012) Equal-area radial crater counts at large Copernican impact craters: implications for late-stage ejecta emplacement? In: Abstracts of 43rd lunar and planetary science conference, Houston, 19-23 March 2012

Zanetti M, Stadermann A, Jolliff B, van der Bogert CH, Hiesinger H, Plescia JB (2015) Auto-secondary cratering vs target property effects on ejecta blankets of Copernican craters: what are the implications for age dating using small-diameter crater statistics? In: Abstracts of 46th lunar and planetary science conference, Houston, 16-20 March 2015

Zanetti M, Stadermann A, Jolliff B, van der Bogert CH, Hiesinger H, Plescia JB (2017) Evidence for self secondary cratering of Copernican-age continuous ejecta deposits on the Moon. Icarus. https://doi.org/10.1016/j.icaru s.2017.01.030

\section{Submit your manuscript to a SpringerOpen ${ }^{\circ}$ journal and benefit from:}

- Convenient online submission

- Rigorous peer review

- Open access: articles freely available online

- High visibility within the field

- Retaining the copyright to your article

Submit your next manuscript at $\gg$ springeropen.com 